\title{
Pediatric kidney transplantation: a historical review
}

\author{
Priya S. Verghese ${ }^{1}$
}

Successful renal transplantation is the optimal treatment for chronic kidney failure, but this was not always so for children. Beginning with the first kidney transplants in the 1950s, children experienced poorer patient and graft survival rates than adult patients. But over the last 6 decades, an improved understanding of the immune system which has steered pediatric multi-center clinical/pharmacokinetic and mechanistic studies that have sculpted our immunosuppression with markedly better patient and graft survivals. In addition, uniquely pediatric issues related to growth, development, neurocognitive maturation, increased complications from primary viral infections, and comorbid congenital/inherited disorders, are now diagnosed and effectively managed in these children. Refined pretransplant preparation (vaccinations for preventable diseases, attention to cognitive delays, effective dialysis and nutrition) improved donor selection, and more potent immunosuppression have all contributed to enhanced outcomes. Similarly, improvements in pediatric surgical techniques, postoperative care and better antiviral prophylaxis have all shortened hospitalizations and reduced morbidity. Today pediatric kidney transplant outcomes are markedly improved and younger children today experience better long-term graft survival than adults! While difficult problems remain, we have made tremendous progress and anticipate even more advances in the future of pediatric kidney transplantation.

W hile renal transplantation quickly became an accepted and preferred mode of therapy in adults, $60 \mathrm{y}$ ago children were allowed to die of renal failure. This was due to the ethical conundrum of the benefit versus risk of aggressive therapy in children with renal failure. While in some countries this remains a reality, this is no longer the case in many places. In fact, in the United States, children get priority on the waitlist for the best deceased donor kidneys. The field of pediatric kidney transplant continues to evolve and children today have outstanding immunosuppression and antiviral options with transplant outcomes that are often better than adults (1). However, there were tragedies and losses as we learned and grew from experience. This review describes the journey and progress the field of pediatric kidney transplantation has made over the last five decades from clinical practice (with an emphasis on the United States) over the last $50 \mathrm{y}$.

\section{SURGICAL AND MEDICAL CONSIDERATIONS BEFORE AND DURING TRANSPLANT}

In 1954, Joseph Murray, a plastic surgeon, performed the first successful kidney transplant on the Herrick brothers, adult identical twins; and the field of transplant surgery was born (Figure 1). In 1959, Gordon Murray, in Toronto, carried out the first successful non-twin sibling transplant. A few years later organ procurement from a brain-dead heart-beating donor was performed (2,3). While some aspects of kidney transplantation were similar for children and adults, the surgical approach varied and technical challenges were great in small children (4-6). Prolonged pediatric dialysis was fraught with issues related to dialysis access, nutrition, growth, bone disease, and developmental and neuro-cognitive delays (7-9). But transplantation often remained a nonviable option with worse outcomes than dialysis partly due to the intuitive belief that pediatric recipients needed pediatric donors (10). The paucity of pediatric deceased donors; and the near-absence of pediatric living donors disadvantaged children waiting for kidneys. Complicating issues was the observed high rate of graft loss, often due to thrombosis upon matching very young donors to very young recipients (11). Today, size and age matching is generally not required in kidney transplantation and smaller children are transplanted via a mid-line incision into the peritoneal cavity. Depending on the size of the child and the blood vessels, the renal vein was anastomosed to the side of the inferior vena cava or common iliac vein and the arterial anastomosis was performed to the side of the aorta or the common iliac artery with good success (12-14) as it still is today. Kidneys from very small pediatric deceased donors are now transplanted en bloc (both kidneys together, attached to a single segment of the aorta and vena cava) into adults with excellent results (15).

Initial reports of very poor outcomes in younger children (16) were followed by studies highlighting the importance of adequate pretransplant preparation and shorter duration on dialysis (7). There was also growing awareness of the importance of improved donor-recipient matching, advantages of living related donors and the critical role of an integrated team of pediatric nephrologists, transplant surgeons, anesthesiologists, dialysis and transplant nurses and coordinators, pediatric infectious disease specialists, social workers, psychologists, dieticians, intensive care unit physicians, etc. In 1982, 12

'Pediatric Nephrology, University of Minnesota Masonic Children's Hospital, Minneapolis, Minnesota. Correspondence: Priya S. Verghese (pverghes@umn.edu) Received 11 May 2016; accepted 30 September 2016; advance online publication 16 November 2016. doi:10.1038/pr.2016.207 


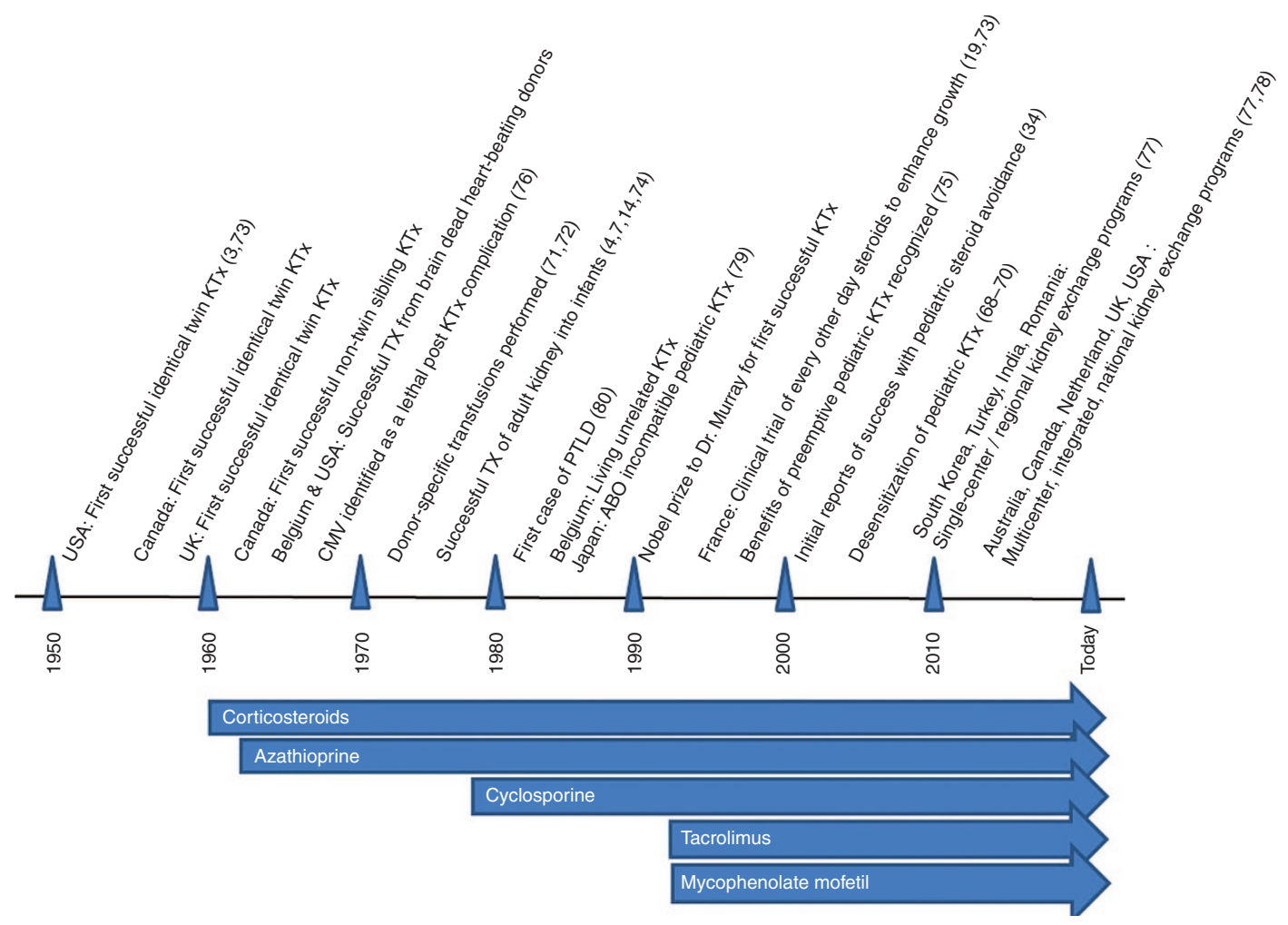

Figure 1. A timeline of some of the milestones in the history of pediatric kidney transplantation. The journey spans more than six decades and involves several continents, countries and patients.

children all under $9 \mathrm{~kg}$ were transplanted an adult kidney with only two reported deaths and two graft losses which was comparable to the adult outcomes at that time (7). Severe growth retardation and psychomotor delay, was initially considered a contra-indication to transplant, but in fact transplant was beneficial in many for catch up growth and development $(17,18)$ and elegant studies were done to optimize growth despite steroid inclusive immunosuppression regimens (19). Today, earlier transplant is actively pursued in children with renal failure and it is more often than not considered unethical to withhold dialysis/transplant from children with renal failure even in the setting of comorbidities.

While specifics of the transplant surgery itself are not explored in this paper, surgical techniques have improved including but not limited to urologic pretransplant bladder preparation, donor nephrectomies which today are frequently done laparoscopically and recipient native nephrectomies which previously universal are now done only if clinically indicated. Even pretransplant preparation has evolved with the availability of growth hormone, epoetin alpha, and various modalities of at-home and in-center dialysis.

\section{PEDIATRIC IMMUNOSUPPRESSION:THEN AND NOW}

Many of our initial transplant failures were due to inappropriate immunosuppression. New immunosuppression in children was studied most often if there were preliminary safety and efficacy data from adult studies. Smaller numbers of pediatric recipients also reduced the capacity for adequately powered randomized controlled trials and so the field of pediatric kidney transplant has mirrored but remained a step behind that of the adult kidney transplant.

Initial immunosuppression involved total body irradiation and splenectomy leading to unacceptably high death rates from overwhelming infection and sepsis (20) followed by an era of unacceptably high rejection rates with steroids alone. The 1960s heralded the development of 6-mercaptopurine, followed by azathioprine; the development of a polyclonal antilymphocyte globulin; and the ability to do histocompatibility and preformed cytotoxic antibody testing to better match donors and recipients $(21,22)$. After the first initially successful series of transplantations performed between 1962 and 1964, azathioprine and steroids became the primary immunosuppressive regimen for the next two decades. In 1967, the first polyclonal antilymphocyte globulin was utilized which spawned the development of other polyclonal and monoclonal antibodies including Minnesota Anti-Lymphocyte Globulin, Thymoglobulin and OKT3. Newer induction agents include but are not limited to Basiliximab and Campath. In children, data today remain limited on the optimal induction therapy.

As knowledge of the immune system has evolved, therapy targeted to specific immune-regulatory sites has become possible. Cyclosporine, introduced in the 1980s, a calcineurin inhibitor, was used in combination with azathioprine and steroids and was credited with a dramatic improvement in graft survival $(23,24)$. In 1994, mycophenolate mofetil (25-27) was introduced and over the past two decades has almost universally 


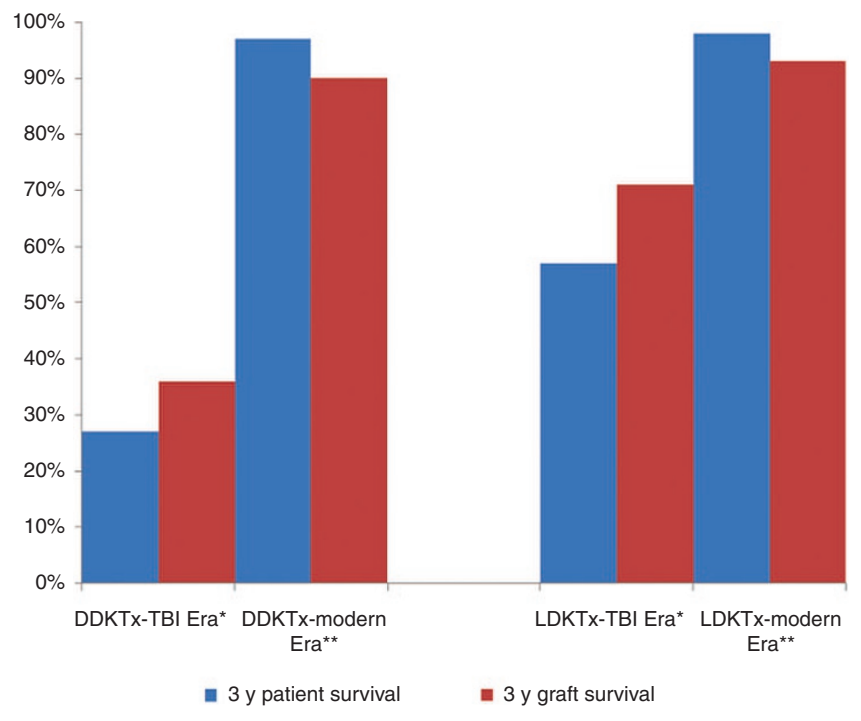

Figure 2. Patient and graft survival in the early days of transplant compared to the modern era for living and deceased donor kidney recipients. Of note, graft and patient survival remain the same since the 1970s with same surgical techniques as during the pioneering period. Therefore, despite the improvement in outcomes following initial transplantation, nonsurgical components of kidney transplantation remain imperfect over the last five decades; and indefinite functioning of kidney transplants without immunosuppression remains a target for the next 50 years. ${ }^{*} \mathrm{TBI}$ Total Body Irradiation. **Post-TBI Era.

replaced azathioprine. After tacrolimus (another calcineurin inhibitor) became available in 1994, debate followed regarding which calcineurin inhibitor was superior; and it has gradually supplanted cyclosporine in many pediatric centers. To expand the armamentarium further, sirolimus (Rapamune), a macrolide antibiotic, was developed and released. Today, there are many other immunosuppressive agents available on the market including belatacept targeting the costimulatory pathway and tocilizumab a humanized monoclonal antibody that binds the IL-6 receptor. Nevertheless, many of these newer agents are yet to be used with confidence in children.

While the purpose of this review is not to dwell on the details of any one immunosuppression, mention of the evolving role of steroids is important. Once a cornerstone of transplant immunosuppression, parental and patient aversion to steroids has driven our field to steroid avoidance regimens. Prospective multi-center trial groups summarized in a recent review (28) have shown glucocorticoid avoidance is not immunologically detrimental, but is associated with chronic histologic damage (29). In addition, high doses of immunosuppressive drugs used to compensate for glucocorticoid withdrawal have an unacceptably high rate of post-transplant lymphoproliferative disorder (30). Similarly tacrolimus, almost universally used for pediatric kidney transplant immunosuppression is now losing favor and studies are considering their necessity $(31,32)$.

Assessing newer immunosuppressive agents in children is challenging since pediatrics represents a very small percentage of the total kidney transplants. Retrospective data registries such as the North American Pediatric Renal Trials and Collaborative Studies, combined adult and pediatric registries such as the United Network for Organ Sharing, the United States Renal Data System, the Collaborative Transplant Study, the Australia and New Zealand Dialysis and Transplant Registry, and the newly formed Cooperative European Pediatric Renal Transplant Initiative Registry in Europe have improved prevalence data. But they are all limited, retrospective and have inherent issues related to data collection methods.

Pediatric metabolism cause different drug processing capacity and dosing of immunosuppression. Therefore, despite outstanding adult transplant studies, meticulous pediatric pharmacokinetic studies have been invaluable in accurately dosing immunosuppression in children $(24,25,33,34)$. In addition, unique features of the pediatric immune system have been studied in numerous mechanistic studies (35-37).

The pendulum continues to swing between over and underimmunosuppression and as researchers and clinicians attempt to find the balance, novel research continues. Immune cell function assays to measure patient cell-mediate immunity on an individual basis have not been successful (38) and the establishment of antigen-specific tolerance to the kidney transplant is not yet a reality in pediatrics (39).

\section{PEDIATRIC KIDNEY TRANSPLANT OUTCOMES \\ Patient Survival and Post-Transplant Infection Burden}

Following unacceptably high mortality in the initial transplant recipients due to overwhelming infections, caution and weaker immunosuppression lead to unacceptable high rejection rates that have reduced with modern immunosuppression (Figure 2). In 1971, the results of 58 infant and pediatric kidney recipients, the youngest being 2 mo of age (7) were reported. Prior to 1968, during the era of total body irradiation, mortality rates were staggering particularly for deceased donor kidney recipients (DDKT) (8 of 11 DDKT patients died within the 3-y follow-up period of sepsis and other infectious complications). The introduction of Minnesota AntiLymphocyte Globulin and cessation of total body irradiation, improved patient survival dramatically with 3-y death rates of $29 \%$ in DDKT although in living donor recipients it was as low as $4 \%(7)$. These results were similar to other pioneer centers doing kidney transplantation in children at that time (18).

Today infection is now the dominant cause of pediatric hospitalizations and death after transplant (40) and many infectious agents are oncogenic; dramatically increasing the lifetime risk of cancer for pediatric transplant recipients. "Transplant lung" was a febrile pulmonary symptom seen in many early kidney transplant recipients. Although initially considered as immunologic, it was soon realized to be an infectious process due to cytomegalovirus (CMV). In early kidney transplants, more than $50 \%$ of deaths were attributed to CMV $(41,42)$ making the discovery of valganciclovir, an anti-CMV drug, one of the most critical and pivotal advances in the field of kidney transplantation. Valganciclovir has particularly galvanized pediatric kidney transplant since pediatric patients are at higher risk for post-transplant CMV due to the higher prevalence of CMV antibody negativity in children. Today valganciclovir is used for therapy and universal prophylaxis against 


\section{Review | Verghese}

CMV. The marrow suppressive side effects of valganciclovir have prompted studies to find alternative antiviral drugs and preventive measures (43) and currently a randomized controlled trial comparing valacyclovir and valganciclovir is in progress at the University of Minnesota. Other deleterious viruses in transplant include the Epstein-Barr virus, known for its potential to cause a premalignant post-transplant lymphoproliferative disorder and $\mathrm{BK}$ virus, a papova virus, which can cause BK nephropathy leading to graft loss $(44,45)$.

Unique issues related to growth, development, and neurocognitive maturation, the increased risk for primary infections, and complications related to congenital/inherited disorders (the most common cause of renal failure in children) are now recognized in children. Awareness has caused more judicious use of immunosuppression aided by advances in antiviral therapy and research is underway to develop immunosuppressants with antiviral and antioncologic properties $(46,47)$. The advent of modern vaccinations, a new genre of anti-infectives, and the results of several novel studies to identify the role of the donor in posttransplant recipient infections and to reduce donor transmission of these viruses (48-50) continue to shape the field of pediatric kidney transplantation. Not surprisingly patient survival has markedly improved, with pediatric patient survival at $3 \mathrm{y}>95 \%$ in deceased and living donor recipients of all ages (51-53).

\section{Graft Survival and Rejection Rates}

Graft survival has also improved with surgical experience, better pretransplant recipient preparation, adult kidney to pediatric recipient transplants, improved induction and maintenance immunosuppression and better donor-recipient matching; with a consequent reduction in technical failures and hyperacute rejection (Figure 2). In one of the largest pediatric transplant centers at the time, the reported graft survival was 71 and $36 \%$ at $3 y$ of transplant for living and deceased donor recipients respectively prior to the utilization of Minnesota AntiLymphocyte Globulin induction therapy. This has improved to 96 and $86 \%$ of living donor and DDKT at $3 y$ following the advent of induction immunosuppression and maintenance with azathioprine and steroids (7). Similar pediatric kidney graft outcomes were reported by others during this era $(10,18)$. Since then short-term graft survival has shown consistent improvement (53). Long-term graft outcomes have plateaued for reasons that are not well-defined.

While modern immunosuppression has bridged the outcome gap between deceased and living donor kidney transplants, living donor graft outcomes remain superior. Recurrence of primary glomerular diseases such as focal segmental glomerulosclerosis and nonadherence remains highly problematic adversely affecting graft outcomes. However, there remains no reliable solution to either problem at this time.

Rejection rates initially as high as $80-90 \%$ is currently $10 \%$ in most pediatrics transplant centers. However, exact comparison of rejection then and now is impossible due to different diagnostic definitions of rejection; the reduction in the incidence of rejection is definite. In addition to advances mentioned above, safer ultrasound guided transplant biopsy techniques, which have increased the yield and number of biopsies per transplant patient with a decrease in morbidity. Surveillance biopsies and the Banff diagnostic pathology guidelines for the diagnosis and staging of rejection have also added greatly to the field; as has the ever-growing range of modern therapies to treat acute cellular and antibody mediated rejection. Research is underway to find noninvasive biomarkers of acute rejection that might replace transplant biopsy $(54,55)$ and shed mechanistic light on rejection allowing for more targeted therapy.

Early studies in patients with a primary graft loss due to rejection showed that retransplantation was associated with poor outcomes $(56,57)$. Nevertheless, with better immunosuppression, this appears to be less of an issue. Prior graft loss to nonadherence is still associated with increased graft loss to nonadherence after retransplant and we appear to be no closer to solving the problem of nonadherence as we were $40 \mathrm{y}$ ago $(58,59)$.

\section{Access to Pediatric Kidney Transplantation}

Although children make up only a small fraction of persons awaiting kidney transplantation, today they have been afforded exceptional societal benefits in many countries while in others despite excellent graft outcomes, they remain disadvantaged and neglected due to socio-economic and cultural issues (60). The current kidney allocation scheme in the United States preferentially allocates higher-quality kidneys from deceased donors to children in relatively prompt fashion (61) with an unintended decline in the donation of kidneys from living donors; a greater proportion of poorly HLA-matched kidney transplants from deceased donors in children (1); a reduction in racial disparities in access to pediatric kidney transplantation (62).

The 21st century has also seen a dramatic change in the transition of print media (newspapers, magazines) to electronic media. Since the birth of the internet almost $30 \mathrm{y}$ ago, there has been an information explosion and the imbalance in the need for a kidney transplant and the availability of these organs is now a highly publicized topic as is the minimal morbidity for kidney donors $(63,64)$ and comparable graft and patient outcomes for living donor kidney recipients regardless of whether the donor is related or not $(65,68)$. Therefore media appeals for kidney donors are gaining popularity (67) and living unrelated kidney donation is on the rise. While the ethics of organ donation has always been a sensitive issue, in this modern era of unrelated donors, it is becoming all the more relevant.

While this review focuses on the developed world, in many developing nations, children with kidney failure have limited access to dedicated pediatric nephrology and do not have the option of kidney transplant. Even centers that perform kidney transplant have unacceptably high infection rates and mortality. There remains much to be done.

\section{SUMMARY}

In summary, since the first pediatric kidney transplant in the 1960s, the field of pediatric kidney transplantation has come a long way. We have made major advances in 
immunosuppression, surgical technique, medical management pre-, peri-, and postoperatively, donor-recipient matching, deceased donor kidney allocation, infection prevention and treatment, better recipient and donor selection and preparation with a multi-disciplinary team approach and of course the multi-center randomized controlled trials that have allowed for meaningful outcome analysis.

However, pediatric kidney recipients still die of infections; post-transplant lymphoproliferative disorders and malignancy remain a very real risk; recurrent focal segmental glomerulosclerosis is yet to have a cure; long-term graft attrition remains an issue; tolerance where patients could be weaned off maintenance immunosuppression is currently far from reach; and nonadherence remains a critical and often unsurmountable detriment to graft survival.

No single review article, can truly address all the critical areas that have shaped the field of pediatric kidney transplant. There is much left unsaid in this manuscript on nonadherence, recurrent disease, rare diseases, cardiovascular disease, post-transplant lymphoproliferative disorder, growth and bone disease, quality of life, reasons for the plateau in long-term outcomes, transplant glomerulopathy, and other viral infections than are covered here. In conclusion, the advancement and progress in pediatric kidney transplantation in the developed world is awe-inspiring with still much to be done. Access to pediatric kidney transplantation in developing nations remains suboptimal. As history has shown, careful and methodical prospective multicenter work is critical in advancing our field and while problems remain, the progress made to date promises more advances in the future for pediatric patients requiring kidney transplantation.

\section{ACKNOWLEDGMENTS}

I would like to sincerely thank Thomas Nevins for his thoughtful suggestions and edits of this manuscript.

\section{STATEMENT OF FINANCIAL SUPPORT}

None.

\section{REFERENCES}

1. Moudgil A, Dharnidharka VR, Lamb KE, Meier-Kriesche HU. Best allograft survival from share-35 kidney donors occurs in middle-aged adults and young children-an analysis of OPTN data. Transplantation 2013;95:319-25.

2. Squifflet JP. The history of transplantation at the Catholic University of Louvain Belgium 1963-2003. Acta Chir Belg 2003;103(3 Spec No):10-20.

3. Murray JE, Tilney NL, Wilson RE. Renal transplantation: a twenty-five year experience. Ann Surg 1976;184:565-73.

4. Miller LC, Lum CT, Bock GH, Simmons RL, Najarian JS, Mauer SM. Transplantation of the adult kidney into the very small child. Technical considerations. Am J Surg 1983;145:243-7.

5. Cochat P, Martin X, Floret D, et al. Successful cadaveric renal transplantation in small children. Transplant Proc 1994;26:271.

6. Rosenthal JT, Ettenger RB, Ehrlich RM, Fine RN. Technical factors contributing to successful kidney transplantation in small children. J Urol 1990;144:116-9.

7. Miller LC, Bock GH, Lum CT, Najarian JS, Mauer SM. Transplantation of adult kidney into the very small child: long-term outcome. J Pediatr 1982;100:675-80.

8. Davis ID, Chang PN, Nevins TE. Successful renal transplantation accelerates development in young uremic children. Pediatrics 1990;86:594-600.

9. Crittenden MR, Holliday MA, Piel CF, Potter DE. Intellectual development of children with renal insufficiency and end stage disease. Int J Pediatr Nephrol 1985;6:275-80.
10. Fine RN, Brennan LP, Edelbrock HH, Riddell H, Stiles Q, Lieberman E. Use of pediatric cadaver kidneys for homotransplantation in children. JAMA 1969;210:477-84.

11. Harmon WE, Alexander SR, Tejani A, Stablein D. The effect of donor age on graft survival in pediatric cadaver renal transplant recipients-a report of the North American Pediatric Renal Transplant Cooperative Study. Transplantation 1992;54:232-7.

12. Najarian JS, Simmons RL, Tallent MB, et al. Renal transplantation in infants and children. Ann Surg 1971;174:583-601.

13. Chavers B, Najarian JS, Humar A. Kidney transplantation in infants and small children. Pediatr Transplant 2007;11:702-8.

14. Salvatierra O Jr, Singh T, Shifrin R, et al. Successful transplantation of adult-sized kidneys into infants requires maintenance of high aortic blood flow. Transplantation 1998;66:819-23.

15. Dharnidharka VR, Stevens G, Howard RJ. En-bloc kidney transplantation in the United states: an analysis of united network of organ sharing (UNOS) data from 1987 to 2003. Am J Transplant 2005;5:1513-7.

16. Moel DI, Butt KM. Renal transplantation in children less than 2 years of age. J Pediatr 1981;99:535-9.

17. So SK, Chang PN, Najarian JS, Mauer SM, Simmons RL, Nevins TE. Growth and development in infants after renal transplantation. J Pediatr 1987;110:343-50.

18. Lilly JR, Giles G, Hurwitz R, et al. Renal homotransplantation in pediatric patients. Pediatrics 1971;47:548-57.

19. Broyer M, Guest G, Gagnadoux MF. Growth rate in children receiving alternate-day corticosteroid treatment after kidney transplantation. J Pediatr 1992;120:721-5.

20. Murray JE, Merrill JP, Dammin GJ, et al. Study on transplantation immunity after total body irradiation: clinical and experimental investigation. Surgery 1960;48:272-84.

21. Terasaki PI, Vredevoe DL, Mickey MR. Serotyping for homotransplantation. X. Survival of 196 grafted kidneys subsequent to typing. Transplantation 1967;5:Suppl:1057-70.

22. Terasaki PI, Mickey MR, Singal DP, Mittal KK, Patel R. Serotyping for homotransplantation. XX. Selection of recipients for cadaver donor transplants. N Engl J Med 1968;279:1101-3.

23. Starzl TE, Weil R 3rd, Iwatsuki S, et al. The use of cyclosporin A and prednisone in cadaver kidney transplantation. Surg Gynecol Obstet 1980;151: $17-26$.

24. Bökenkamp A, Offner G, Hoyer PF, Vester U, Wonigeit K, Brodehl J. Improved absorption of cyclosporin A from a new microemulsion formulation: implications for dosage and monitoring. Pediatr Nephrol 1995;9:196-8.

25. Bunchman T, Navarro M, Broyer M, et al. The use of mycophenolate mofetil suspension in pediatric renal allograft recipients. Pediatr Nephrol 2001;16:978-84.

26. Ettenger R, Cohen A, Nast C, Moulton L, Marik J, Gales B. Mycophenolate mofetil as maintenance immunosuppression in pediatric renal transplantation. Transplant Proc 1997;29:340-1.

27. Staskewitz A, Kirste G, Tönshoff B, et al. Mycophenolate mofetil in pediatric renal transplantation without induction therapy: results after 12 months of treatment. German Pediatric Renal Transplantation Study Group. Transplantation 2001;71:638-44.

28. Dharnidharka VR, Fiorina P, Harmon WE. Kidney transplantation in children. N Engl J Med 2014;371:549-58.

29. Naesens M, Salvatierra O, Benfield M, et al.; SNS01-NIH-CCTPT Multicenter Trial. Subclinical inflammation and chronic renal allograft injury in a randomized trial on steroid avoidance in pediatric kidney transplantation. Am J Transplant 2012;12:2730-43.

30. McDonald RA, Smith JM, Ho M, et al.; CCTPT Study Group. Incidence of PTLD in pediatric renal transplant recipients receiving basiliximab, calcineurin inhibitor, sirolimus and steroids. Am J Transplant 2008;8:984-9.

31. Verghese PS, Dunn TB, Chinnakotla S, Gillingham KJ, Matas AJ, Mauer MS. Calcineurin inhibitors in HLA-identical living related donor kidney transplantation. Nephrol Dial Transplant 2014;29:209-18.

32. Grinyo JM, Campistol JM, Paul J, et al. Pilot randomized study of early tacrolimus withdrawal from a regimen with sirolimus plus tacrolimus in kidney transplantation. Am J Transplant 2004;4:1308-14.

33. Schachter AD, Meyers KE, Spaneas LD, et al. Short sirolimus half-life in pediatric renal transplant recipients on a calcineurin inhibitor-free protocol. Pediatr Transplant 2004;8:171-7. 
34. Sarwal MM, Yorgin PD, Alexander S, et al. Promising early outcomes with a novel, complete steroid avoidance immunosuppression protocol in pediatric renal transplantation. Transplantation 2001;72:13-21.

35. Zarkhin V, Lovelace PA, Li L, Hsieh SC, Sarwal MM. Phenotypic evaluation of B-cell subsets after rituximab for treatment of acute renal allograft rejection in pediatric recipients. Transplantation 2011;91:1010-8.

36. De Serres SA, Mfarrej BG, Magee $\mathrm{CN}$, et al. Immune profile of pediatric renal transplant recipients following alemtuzumab induction. J Am Soc Nephrol 2012;23:174-82.

37. Knechtle SJ. Present experience with Campath-1H in organ transplantation and its potential use in pediatric recipients. Pediatr Transplant 2004;8:106-12.

38. Wang Z, Liu X, Lu P, et al. Performance of the ImmuKnow assay in differentiating infection and acute rejection after kidney transplantation: a meta-analysis. Transplant Proc 2014;46:3343-51.

39. Sarwal MM. Fingerprints of transplant tolerance suggest opportunities for immunosuppression minimization. Clin Biochem 2016;49:404-10.

40. Kirk AD, Mannon RB, Swanson SJ, Hale DA. Strategies for minimizing immunosuppression in kidney transplantation. Transpl Int 2005;18:2-14.

41. Rifkind D, Goodman N, Hill RB Jr. The clinical significance of cytomegalovirus infection in renal transplant recipients. Ann Intern Med 1967;66:1116-28.

42. Fine RN, Grushkin CM, Anand S, Lieberman E, Wright HT Jr. Cytomegalovirus in children. Am J Dis Child 1970;120:197-202.

43. Reischig T, Kacer M, Jindra P, Hes O, Lysak D, Bouda M. Randomized trial of valganciclovir versus valacyclovir prophylaxis for prevention of cytomegalovirus in renal transplantation. Clin J Am Soc Nephrol 2015;10:294-304.

44. Gardner SD, Field AM, Coleman DV, Hulme B. New human papovavirus (B.K.) isolated from urine after renal transplantation. Lancet 1971;1: 1253-7.

45. Drake KA, Najera L, Reed RC, Verghese PS. Unusual presentations of BK virus infections in pediatric renal transplant recipients. Pediatr Transplant 2013;17:E9-15.

46. Wali RK, Drachenberg C, Hirsch HH, et al. BK virus-associated nephropathy in renal allograft recipients: rescue therapy by sirolimus-based immunosuppression. Transplantation 2004;78:1069-73.

47. Morath C, Arns W, Schwenger V, Mehrabi A, Fonouni H, Schmidt J, et al. Sirolimus in renal transplantation. Nephrology, dialysis, transplantation: official publication of the European Dialysis and Transplant Association European Renal Association. 2007;22 Suppl 8:viii61-viii5.

48. Verghese PS, Schmeling DO, Knight JA, Matas AJ, Balfour HH Jr. Valganciclovir administration to kidney donors to reduce the burden of cytomegalovirus and Epstein-Barr virus transmission during transplantation. Transplantation 2015;99:1186-91.

49. Cen H, Atchison RW, Ho M, McKnight JL. Epstein-Barr virus transmission via the donor organs in solid organ transplantation. J Virol 1991;65: 1976-80.

50. Verghese PS, Schmeling DO, Knight JA, Matas AJ, Balfour HH Jr. The impact of donor viral replication at transplant on recipient infections posttransplant: a prospective study. Transplantation 2015;99:602-8.

51. North American Pediatric Renal Trials and Cooperative Studies (NAPRTCS). 2014 annual transplant report. https://web.emmes.com/ study/ped/annlrept/annualrept2014.pdf.

52. Matas AJ, Smith JM, Skeans MA, Lamb KE, Gustafson SK, Samana CJ, et al. OPTN/SRTR 2011 Annual Data Report: kidney. Am J Transplant 2013;13 Suppl 1:11-46.

53. Matas AJ, Smith JM, Skeans MA, Thompson B, Gustafson SK, Stewart DE, et al. OPTN/SRTR 2013 Annual Data Report: kidney. Am J Transplant. 2015;15 Suppl 2:1-34.

54. Suthanthiran M, Schwartz JE, Ding R, et al.; Clinical Trials in Organ Transplantation 04 (CTOT-04) Study Investigators. Urinary-cell mRNA profile and acute cellular rejection in kidney allografts. N Engl J Med 2013;369:20-31.

55. Halloran PF, Famulski K, Reeve J. The molecular phenotypes of rejection in kidney transplant biopsies. Curr Opin Organ Transplant 2015;20:359-67.

56. Gifford RW Jr, Deodhar SD, Stewart BH, Nakamoto S, Shibagaki M, Kolff WJ. Retransplantation after failure of first renal homografts. Studies in 19 patients. JAMA 1967;199:799-804.

57. Casali R, Simmons RL, Ferguson RM, et al. Factors related to success or failure of second renal transplants. Ann Surg 1976;184:145-54.
58. Dunn TB, Browne BJ, Gillingham KJ, et al. Selective retransplant after graft loss to nonadherence: success with a second chance. Am J Transplant 2009;9:1337-46.

59. Korsch BM, Fine RN, Negrete VF. Noncompliance in children with renal transplants. Pediatrics 1978;61:872-6.

60. Sibal A, Malhotra S, Guru FR, et al. Experience of 100 solid organ transplants over a five-yr period from the first successful pediatric multi-organ transplant program in India. Pediatr Transplant 2014;18:740-5.

61. Organ Procurement and Transplantation Network. Policy 11: Allocation of Pancreas, Kidney-Pancreas, and Islets, 2016. (https://optn.transplant.hrsa. gov/media/1200/optn_policies.pdf.)

62. Amaral S, Patzer RE, Kutner N, McClellan W. Racial disparities in access to pediatric kidney transplantation since share 35. J Am Soc Nephrol 2012;23:1069-77.

63. Najarian JS, Chavers BM, McHugh LE, Matas AJ. 20 years or more of follow-up of living kidney donors. Lancet 1992;340:807-10.

64. Ibrahim HN, Foley R, Tan L, et al. Long-term consequences of kidney donation. N Engl J Med 2009;360:459-69.

65. D’Alessandro AM, Sollinger HW, Knechtle SJ, et al. Living related and unrelated donors for kidney transplantation. A 28-year experience. Ann Surg 1995;222:353-62; discussion 362-4.

66. Park K, Kim YS, Lee EM, Lee HY, Han DS. Single-center experience of unrelated living-donor renal transplantation in the cyclosporine era. Clin Transpl 1992:249-56.

67. Verghese PS, Garvey CA, Mauer MS, Matas AJ. Media appeals by pediatric patients for living donors and the impact on a transplant center. Transplantation 2011;91:593-6.

68. Al-Uzri AY, Seltz B, Yorgin PD, Spier CM, Andreoni K. Successful renal transplant outcome after intravenous gamma-globulin treatment of a highly sensitized pediatric recipient. Pediatr Transplant 2002;6: 161-5.

69. Valentini RP, Nehlsen-Cannarella SL, Gruber SA, et al. Intravenous immunoglobulin, HLA allele typing and HLAMatchmaker facilitate successful transplantation in highly sensitized pediatric renal allograft recipients. Pediatr Transplant 2007;11:77-81.

70. Pradhan M, Raffaelli RM, Lind C, et al. Successful deceased donor renal transplant in a sensitized pediatric recipient with the use of plasmapheresis. Pediatr Transplant 2008;12:711-6.

71. Salvatierra O Jr, Vincenti F, Amend W, et al. Deliberate donor-specific blood transfusions prior to living related renal transplantation. A new approach. Ann Surg 1980;192:543-52.

72. Salvatierra O Jr, Melzer J, Vincenti F, Amend WJ Jr, Tomlanovich S, Potter D, et al. Donor-specific blood transfusions versus cyclosporine--the DST story. Transplantation Proceedings 1987;19(1 Pt 1):160-6.

73. Leivestad T, Albrechtsen D, Flatmark A, Thorsby E. Renal transplants from HLA-haploidentical living-related donors. The influence of donor-specific transfusions and different immunosuppressive regimens. Transplantation 1986;42:35-8.

74. Salvatierra O Jr, Singh T, Shifrin R, Conley S, Alexander S, Tanney D, et al. Transplantation of adult-sized kidneys into infants induces major blood flow changes. Transplantation Proceedings 1999;31(1-2):236-7.

75. Offner G, Hoyer PF, Meyer B, Pichlmayr R, Brodehl J. Pre-emptive renal transplantation in children and adolescents. Transpl Int 1993;6:125-8.

76. Hill RB Jr, Rowlands DT Jr, Rifkind D. Infectious pulmonary disease in patients receiving immunosuppressive therapy for organ transplantation. N Engl J Med 1964;271:1021-7.

77. Ferrari P, Weimar W, Johnson RJ, Lim WH, Tinckam KJ. Kidney paired donation: principles, protocols and programs. Nephrol Dial Transplant 2015;30:1276-85.

78. Sypek MP, Alexander SI, Cantwell L, Ierino FL, Ferrari P, Walker AM, et al. Optimizing outcomes in pediatric renal transplantation through the Australian Paired Kidney Exchange Program. Am J Transplant 2016; e-pub ahead of print 6 September 2016.

79. Aikawa A, Kawamura T, Shishido S, Saito K, Takahashi K; ABO-Incompatible Transplantation Committee members. ABO-incompatible livingdonor pediatric kidney transplantation in Japan. Clinics (Sao Paulo) 2014;69 Suppl 1:22-7.

80. Hanto DW, Sakamoto K, Purtilo DT, Simmons RL, Najarian JS. The Epstein-Barr virus in the pathogenesis of posttransplant lymphoproliferative disorders. Clinical, pathologic, and virologic correlation. Surgery 1981;90:204-13. 